\title{
The Dynamics of the Indicators of Social Adaptation of Orphaned Children with Limited Health Abilities
}

\author{
Elena Y. Borisova \\ Svetlana L. Shalaeva \\ Irina B. Kozina \\ Mari State University, Yoshkar-Ola, Russia \\ Email: kozira@list.ru
}

\section{Doi:10.5901/mjss.2015.v6n3s7p155}

\begin{abstract}
Relevance of the problem being researched in this article is due to the need creating optimal conditions for successful social development and social adaptation of children regardless of the level of their psychophysical development. The article is devoted to the analysis of dynamics of indicators of social disadaptation, as well as development of the elements of social competence of orphaned children with limited health abilities in the process of implementation a coherent program which includes a model of guest form of placement orphaned children in families and a wide range of learning, educational and correctional-developing programs, the main purpose of which is preparation the students to individual life. The diagnostic results of the students of Oktyabrskaya special boarding school on the first stage reflect quite unfavourable situation marked by various manifestations of disadaptation with dominance of symptoms determining distrust in people, the rejection and anxiety towards adults, inclination to depression and annoyance as well as lack of social normativity. The final results show quite both expressed positive changes that characterize the growth of social competence and the level of social adaptation of students
\end{abstract}

Keywords: orphaned children with limited health abilities, social adaptation, social competence

\section{Introduction}

In contemporary society the timeliness of studying various problems of Childhood is rapidly increasing that is directly related to clear awareness of its role in existence and reproduction at substantive and functional levels of Society and Human nature. The number of studies in this field is constantly growing: cultural-historical theory of psychological development (L.S. Vigotsky , A.R. Luriya, A.N. Leontyev, D.B. Elkonin), ethnography of childhood (M.Mid, I.S. Kon, G.S. Vinogradov), history of childhood (F. Aries), sociology of childhood (V.S.Sobkin, S.N.Shcheglova), ecological psychology of child development (G.V.Burmenskaya, L.F.Obukhova), social-genetic psychology (V.V.Rubtsov), social psychology of childhood (V.V.Abramenkova), ecology of childhood (U.Bronfenbrenner, V.I.Panov), virtual psychology of childhood (N.A.Nosov) and others.

It could be considered as a positive trend, if this enhancing interest was explained with awareness of strategic importance of childhood as a period in personal development and attitude to childhood of a society taking the long view. But in reality this growth of timeliness is explained with combusted and still growing crisis of childhood, which can't help being noticed and responded by adults.

Being a structure element of society, childhood reflects all its problems. Under the conditions of system transformation of society, social and economic, political and cultural updates, childhood itself also goes through revolutionary changes together with its status in society and the specificity of inter-generational relations. The quality of these changes is specified as "modern crisis of Russian childhood" (Elkonin \& Slobodchikov,1992), "unique social situation of development of modern childhood" (Abramenkova, 2000), "technification of the world of childhood" (Shalaeva, 2005) etc.

A new sociocultural era of child life in the modern world is coming with prefigurative culture of translation of intergenerational experience, when in dynamically changing world children adapt to the changes faster and their socioculural experience is adopted by adults. Thus, children and adults participate in mutual development, support each other and bring some risks. Interpenetration of childhood and adult worlds results in acceleration of childhood and 
infantilization of adulthood. The example of metamorphosis of social statuses in child and adult worlds is legitimization and positioning of "inner child" in grown-up subject that combine childishness and adulthood both in interpersonal and personal aspects. Gradually adulthood becomes a thing of no value. Moreover, infant psychological characteristics, symbols, behavior and art forms (spontaneity, emotionality, childishness in creative work etc.) penetrate deeper into the adult world (gamification phenomenon, ageism, Peter Pan Syndrome, popular Feldenkrais movement technique (Shalaeva \& Shalaeva, 2015). It can be stated that the influence of youth leisure activities and extreme sports on the adult world is increasing.

In contemporary social and human knowledge the awareness that childhood is a reality with its own substantial nature, developmental laws and logic, a special self-organizing reality, which has to be researched thoroughly, is growing. Childhood increasingly becomes a subject of social relations instead of being an object of educational influence in the adult world.

The crisis of modern childhood at empirical level is evident in the following psychological aspects:

1) Poralisation of psychological development of children and youngsters by developmental level. The place of normal curve, which traditionally had described the distribution of children and youngsters over developmental level, was taken by three peaks model - middle level of development, advanced level and level located in the zone of underdevelopment.

2) Increasing number of children characterized with negative flow of psychological development. At that, the reasons of developmental delays become ever more various and multiple.

3) Increasing expressiveness of risk factors (biological, social), increasing share of risk groups among children and youngsters and appearance of new risk groups along with traditional ones.

4) Forcing of intellectual development of children and youngsters in the form of artificial acceleration.

5) Changes in motivational sphere towards decrease of cognitive motives and interests, curiosity; increase of importance of consumer interest.

6) Deterioration of the type of emotional attachment in child and parent relationships.

7) Decreasing volume and quality of children's communication with coevals; increasing degree of loneliness and rejection.

The crisis found is explained both with reduction of childhood as a structural element of society and, what is more, deterioration of physical and psychological health in the childhood world. In common sense it is proved with falling birth rates, the increase of infant mortality, observable decline in children's health, the increase of the number of children with developmental delays as well as rising orphanage, homelessness and suicide rates in the childhood world.

At the present time more attention is focused on creating optimal conditions for successful social development and social adaptation of children regardless of the level of their psychophysical development. This is one of the top priorities in education, which is timely because of involving people with reduced health capabilities into the educational system (Borisova \& Kozina, 2015). The acuteness of the problem is determined with stable growth of number of children with special educational needs.

Practical activity of special schools for children with intellectual disability shows that the problems of social adaptation of mentally challenged students are solved yet harder over recent years. The process of orphaned children's entry into society is more difficult as the education in a special boarding school does not provide development of personal qualities, skills and experiences necessary in individual life to the right degree that leads to unsuccess of the graduates in performing tasks of independent life. Intellectual capacity of orphaned children with limited health abilities (LHA) does not make a good basis for learning and individual applying of the wide range of social and other forms of life.

As a consequence of this set of reasons, the process of entry of the VIII-type special boarding school graduates into individual life is difficult. It determines the necessity of researching factors and conditions, which make the integration processes work, and the importance of developing the forms of correctional work in rendering social support and assistance to the students and orphaned graduates of special boarding school.

The existing contradiction between social importance of the problem of adaptation of orphaned children with LAH in modern society and, along with that, its insufficient exploration degree, as well as lack of implementation of many methods in solving the problem, has led to working out the project.

During 5 years (2011-2015) on the basis of government-run educational institution «Oktyabrskaya special boarding school for orphaned children and children without parental support with limited health abilities, VIII type» in Mari El Republic the project named "Social adaptation and preparation to individual life of orphaned children with LHA (through temporary placement in a family)" has been carried out.

The study purpose is argumentation and development of the program of social adaptation and preparation of special boarding school students with intellectual disability to individual life with the application of temporary placement in 
a family.

The study is based on a hypothesis that social adaptation and development of intellectually disabled orphaned students' preparedness to individual life can be successful upon the condition of: focusing of the educational institution on the development of necessary knowledge and skills, on preparing the students to solve main problems of individual life after graduation; development and carrying out a coherent program of social adaptation and preparation of the students to individual life with applying temporary placement in a family; rehabilitation work with the child, which makes him prepared to be placed in a family; building a work system for selection, preparation and evaluation of foster carers; providing psychological and pedagogic support to persons temporary replacing family on all stages.

\section{Methods}

The diagnostic program included the following methods: Stott's examination card, social competence scale (A.M.Prikhozhan), social network questionnaire developed on the basis of Californian social network questionnaire for healthy testees, social skills questionnaire (A.Goldshtein). (Prihozhan \& Tolstyh, 2005). For the purpose of finding the dynamics of indicators of social disadaptation, as well as development of the elements of social competence of orphaned children with LHA, the project included a study consisted of several tests. The study captured all students of the special boarding school but in the context of social competence the most interesting results were received from the graduation class students (8-9 grades).

\section{Results and Discussion}

Stott's examination card consists of 16 complexes of behavior symptoms and samples - symptom complexes. The outcome analysis allows to evaluate the degree of expressiveness of separate symptom complexes and to determine the degree of the students' social disadaptation in a whole. According to the results of primary diagnostics, the biggest expressiveness was peculiar to "Rejection of adults" symptom complex reflecting demonstration of rejection of adults in various forms, which can be the beginning of enmity or depression; in particular cases an open enmity is noted, which is evident as asocial behavior. The indicators of "Weakness" syndrom complex are expressed enough. It reflects various activity and mood swings, inclination to anger and physical exhaustion, depressed moods. High values are also peculiar to LT syndromes - "Lack of trust towards new people, things, situations" and A - "Asociality". These indicators reflect quite unfavourable situation marked by various manifestations of disadaptation with dominance of symptoms determining distrust in people, the rejection and anxiety towards adults, inclination to depression and annoyance as well as lack of social normalization. (Borisova, Shuvarova, Leontyeva, \& Sevastyanov, 2013)

A.M.Prikhozhan's scale is focused on evaluation of the degree of social competence of youngsters. It allows to find out both the general degree of children's social competence in accordance with their age and the competence in particular directions, such as independence, self-confidence, attitude to duties, communication development, being organized, interest to social life. Both self-appraisal and expert appraisal are carried out by the diagnostic indicators. As a result, an opportunity to relate real chronologic age of the students to social age, reflecting social competence of the students, appears. With rare exception, both students and pedagogues appraised the development of such indicators as independence, self-confidence, attitude to duties, communication development and being organized lower the chronologic age and noted the lack of social competence.

Social network appraisal made by the students of senior forms of special boarding school reflects a situation, which makes an unfavorable forecast of further adaptation of the graduates. The social network questionnaire for graduates allows to learn about the youngster's circle of contacts, about people important for him and supporting him emotionally or financially, about people being a behavior sample for him and whose view on life resonates with him. According to the study findings, $48 \%$ of seniors showed low degree of social network development and the social network characteristics of $24 \%$ of students are relevant to social disadaptation.

The correlation analysis of the findings proves the presence of negative trends. In the center of the correlation pleiade, combining the indicators of student disadaptation on the study's first stage, the symptom complex named RA (rejection of adults) takes place. It reflects quite obvious trend explaining the degree of social adaptation disorders of special boarding school students with expressiveness of rejection to adults. The more emnity towards adults is expressed, the higher the values of asociality, self-removal and long-term effort avoidance, proneness to conflict with coevals are, along with high anxiety and disconfidence in whether the coevals admit the child.

As a whole, the correlation analysis findings show the relevance between various symptom complexes of social disadaptation that reflects quite unfavorable situation at high values of these negative parameters. The findings do not 
contradict the common view of difficulties of social disadaptation of orphaned children in a whole and especially children with intellectual incapacity.

What concerns the elements of social competence, the correlations between specific indicators on this stage are rather of identity character. In particular, a higher number of trusted contacts, characterizing the social network, refer to a higher self-appraisal of social skills and the width of social communication field along with weaker self-discipline. Also the study notes direct relationship between independence indicators and attitude to communication, state of being organized and interest to social life. A stable structure of relations between different manifestations of social competence is not found on the first stage.

It is quite interesting that the central indicator of disadaptation, LA symptom complex, turned out not to be directly related to the studied parameters of social competence. Indirect relations between the rejection of adults and the social competence of students allow to review this parameter as a latent factor that has an indirect impact on the success of socialization of the students.

The structure of relations between disadaptation symptom complexes and the parameters of the students' social competence is quite complicated. Among disadaptation syndrome complexes related to the social competence elements are: I - impatience, inadaptability to work requiring assiduity, attention focusing, deliberation, avoiding long-term efforts ( 6 correlations with the elements of social competence); ET - emotional tension or emotional inmaturity (4); O - apathy, low mood (3); LT - lack of trust to new people, things, situations (2); R-self-removal (1); P -physical defects (1) and S manifestations of unfavorability of social environment (2). The biggest number of relationships is peculiar to factor I: impatience, inadaptability to work requiring assiduity, attention focusing, deliberation, avoiding long-term efforts are related to communication development, self-discipline, the lack of which leads to the decrease of social competence in a whole and especially in the attitude to duties, the interest to social life. The lack of trust in new people determines the decrease of number of social supports and educators added to the graduate's social network. In its turn, it will have an adverse effect on the graduate's adaptation beyond the special boarding school. Weakness, apathy and the dominance of low mood lead to insufficient independence and social competence and are reflected in low self-appraisal of social skills.

As a whole, the study findings on the first stage reflect a wide range of the students' adaptation disorders that brings the necessity of particular study of factors and conditions, which determine the success of socialization processes, and the development of technology of correctional work providing social support and assistance to students and orphaned graduates of a special boarding school.

During several years in Oktyabrskaya special boarding school a new form of fostering orphans and children without parental care is practiced - guest fostering. Fostering is an important stage in personality development of an orphaned child with LAH and helps to prepare better to adulthood. As a part of the project implementation, the model of institution activity regarding solution the tasks of social adaptation and preparation the students of VIII-type special boarding school to individual life, with applying temporary placement in a family, was developed. It represents a coherent program including a model of guest form of placement orphaned children with LAH in families and a wide range of learning, educational and correctional-developing programs, the main purpose of which is preparation the students to individual life.

The efficiency of the teacher staff activities on the model implementation can be appraised on the basis of dynamics of indicators of the students' social adaptation and competence. The control diagnostic findings allow to state that the most expressed changes are peculiar to the indicators of social adaptation of the students (table 1).

The diagnostic findings reflect quite expressed positive shifts, as far as a significant reduction is marked almost on all symptom complexes (9 of 16). It reflects a substantial decrease of disadaptation manifestations, despite the fact that the summary indicators are far from the standard values. We should note the changes of the indicators characterizing the expressiveness of apathy and low mood ( $\mathrm{O}$ scale) and the manifestation of various forms of rejection towards adults: from avoidance behavior and suspicion towards teacher to uncontrolled enmity (RA scale). The indicators of social normalization of behavior (A) were improved along with the decrease of anxiety and self-doubts regarding importance and being needed for the adults around (AC). 
Table 1.The dynamics of diagnosable indicators (only important differences are listed)

\begin{tabular}{|l|c|c|c|}
\hline & $\begin{array}{c}\text { Average values according to the } \\
\text { results of the first diagnostics } \\
\text { (May 2011) }\end{array}$ & $\begin{array}{c}\text { Average values according to the results } \\
\text { of the control diagnostics (October } \\
\text { 2012) }\end{array}$ & $\begin{array}{c}\text { Significance of } \\
\text { the differences }\end{array}$ \\
\hline LT - lack of trust in new people, things, situations & 7.2174 & 5.8261 & 0.08 \\
\hline O - weakness (asthenia) & 16.8261 & 8.8696 & 0.0 \\
\hline AAanxiety for admittance by adults and their interest & 5.4783 & 1.8261 & 0.0 \\
\hline RA - rejection of adults & 19.2174 & 9.2609 & 0.0 \\
\hline AC - anxiety for admittance by children & 6.5652 & 2.6957 & 0.0 \\
\hline A- asociality & 11.5217 & 4.9565 & 0.0 \\
\hline CC - conflictness with children & 4.2174 & 2.0435 & 0.001 \\
\hline I- restlesnessorbustling & 5.4783 & 2.3913 & 0.003 \\
\hline ET - emotional tension or emotional inmaturity & 5.5217 & 3.3913 & 0.00 \\
\hline Social disadaptation ratio & 89.4783 & 45.7826 & 0.017 \\
\hline The size of social network & 9.7826 & 6.1000 & 0.005 \\
\hline The number of social supports & 4.6522 & 2.8000 & 0.020 \\
\hline trusted contacts & 3.2174 & 1.5000 & 0.007 \\
\hline Social communication field & 4.6087 & 1.8500 & 0.005 \\
\hline activity fields & 1.8696 & 1.1500 & 0.004 \\
\hline Social skills & 2.9130 & 2.0435 & 0.048 \\
\hline compensation ratio & 0.1905 & 0.4422 & 0.018 \\
\hline Social competence (independence) & 9.0909 & 11.1818 & 0.003 \\
\hline social competence ratio & 0.1045 & 0.0955 & \\
\hline
\end{tabular}

Changes, found according to the results of study of the students' social networks, are not of so positive character. In particular, size reduction of social network, reduction of social support and trusted contacts as well as the compression of social communication and activity are noted. Social competence indicators according to A.M.Prikhozhan did not undergo substantional transformation, except for the independence appraisal. At that, despite the fact that the social competence ratio remained within normal findings, we can see the decrease of competence self-appraisal by the students that may reflect more objective and critical attitude to their personal qualities.

Correlation analysis of the repeat diagnostic study findings also reflects significant changes occurred with the students.

A stable structure combining various indicators of social disadaptation has broken down. The most stable part is LT symptom complex - lack of trust in new people, things, situations that kept the relation to factors I - impatience and avoidance of efforts as well as NS - neurotic symptoms.

In the background of disintegration of social disadaptation indicators, the most interesting thing is strengthening of relationship structure of particular elements of social competence. A close intercorrelation of the indicators, characterizing social networks, social skills and social competence of the students, is noted (table 2).

Table 2. Incorrelation matrix of social competence indicators on the $2^{\text {nd }}$ stage of the study

\begin{tabular}{|c|c|c|c|c|c|c|c|c|c|c|c|c|c|c|c|c|c|}
\hline & \multicolumn{7}{|c|}{ Social networks } & \multicolumn{3}{|c|}{ Social skills } & \multicolumn{7}{|c|}{ Social competence } \\
\hline & $\frac{N}{\omega}$ & 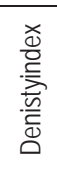 & 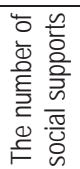 & 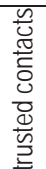 & 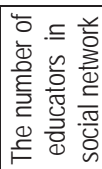 & 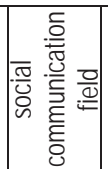 & 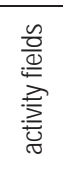 & 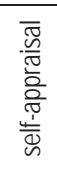 & 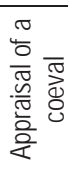 & 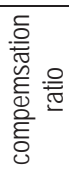 & 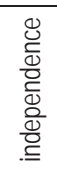 & 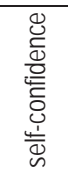 & 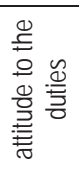 & 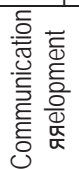 & 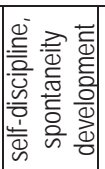 & 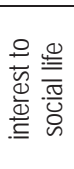 & 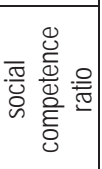 \\
\hline & 1 & 2 & 3 & 4 & 5 & 6 & 7 & 8 & 9 & 10 & 11 & 12 & 13 & 14 & 15 & 16 & 17 \\
\hline 1 & & .540 & $.656^{\text {t* }}$ & & $611^{* *}$ & $666^{* *}$ & $630^{*+4}$ & & & & & & & &,- 487 & 540 & $.656^{\text {th }}$ \\
\hline 2 & & &, $622^{\text {** }}$ & & & $454^{*}$ & & & & & & & & & & & \\
\hline 3 & & & & &, $553^{*}$ & $484^{*}$ & $685^{* *}$ & & & & & & & & & & \\
\hline 4 & & & & & & & & & & & & &,$- 464^{*}$ &,$- 5^{\star}$ &,$- 466^{*}$ & & \\
\hline 5 & & & & & & &, $600^{* *}$ & & & & & & & & & & \\
\hline 6 & & & & & & & & & & & & & & & & & \\
\hline 7 & & & & & & & & $450^{\star}$ & & & & & & & & & \\
\hline 8 & & & & & & & & & $.622^{* *}$ & & $.456^{*}$ & & & & & $464^{*}$ & \\
\hline 9 & & & & & & & & & &,$- 451^{*}$ & & & & & & & \\
\hline 10 & & & & & & & & & & & & & & & & & \\
\hline 11 & & & & & & & & & & & & $816^{\text {** }}$ &, $759^{\text {** }}$ &, $672^{* *}$ & $869^{* *}$ &, $719^{* *}$ &,$- 840^{* *}$ \\
\hline 12 & & & & & & & & & & & & & $696^{\text {*t }}$ &, $693^{* *}$ & $890^{*+*}$ &, $743^{*+}$ &,$- 875^{\star *}$ \\
\hline 13 & & & & & & & & & & & & & &, $776^{\text {** }}$ &, $789^{* *}$ &, $578^{* *}$ &,$- 816^{* *}$ \\
\hline 14 & & & & & & & & & & & & & & &, $798^{* *}$ &, $720^{* *}$ &,$- 779^{* *}$ \\
\hline 15 & & & & & & & & & & & & & & & &, $748^{* *}$ &,$- 819^{* *}$ \\
\hline 16 & & & & & & & & & & & & & & & & &,$- 707^{* *}$ \\
\hline 17 & & & & & & & & & & & & & & & & & \\
\hline
\end{tabular}


The tendency manifested is of positive character because it reflects the disintegration of symptom complexes along with consolidation of social competence elements. However, it doesn't mean final resolving of the problem situation, as the disadaptation degree, despite the expressed decrease, stands in the zone exceeding the average values; at the same time the social competence level stands lower the age norm. Rejection of adults does not play a critical role in social disadaptation of students anymore. Obviously, an essential role in this change was also played by temporary placement in guest families that extends the experience of interaction with social environment in general and with adults in particular. But remained distrust in new people, things, and situations limits the opportunities of development of social networks. In particular, the more the distrust in people is expressed, the less the number of trusted contacts, the number of social supports and the size of social network are, the more limited the social communication and the activity fields are. Social competence manifestations lagging from age norms leads to remaining of infantile forms and conflict methods of interaction.

\section{Conclusion}

Thus, the analysis of the study findings allows to reveal quite contradictory tendencies reflecting both expressed positive changes, which point to the increase of social competence and the degree of social adaptation of the students, and remaining difficulties related, most of all, with the extension of social interaction field.

Socialization assumes not only a certain level of labor adaptation of a graduate but also the opportunity to orient in life with observing certain rules and behavior norms. In this regard, at the present day the task of prime importance is the development of social competence of children with LHA. Social competence is, on the one hand, a set of knowledge and skills providing successful coexistence of a person in social space and on the other hand this is a human ability to build the strategies of interaction with other people in surrounding social reality being constantly changed.

It determines the necessity of further studies focused on finding the psychological-pedagogic conditions of social competence development of orphaned children with LHA.

Above are some of the multiple particular proofs of crisis of Childhood World as well as relations between Adult and Childhood worlds, which are related most of all with the specialties of the adults' performance of their mediation functions.

The sociocultural phenomenon of childhood is a problem of strategical importance for theoretical and practical study. Within this framework, the necessity to constantly monitor the current state of childhood and to develop a set of correctional and preventative measures for the observed crisis phenomena is arising. By and large, in modern sociohumanistic knowledge a new awareness gains momentum - the awareness of upcoming necessity for a new scientific paradigm of description and management of ever more complex and instable social reality; that childhood is a reality with its own substantial nature, developmental laws and logic; that this is a special self-organizing reality, which needs to be explored deeply and thoroughly.

\section{References}

Abramenkova, V.V. (2000). Social psychology of childhood: development of child's relationships in infant subculture. Moscow Voronezh: MODEK

Borisova, E..Shuvarova, S, Leontyeva, N,.\&Sevastyanov, V. (2013). The features of social adaptation of orphans with mental retardation. European Child+Adolescent Psychiatry, Vol.22, Supplement 2, p.247

Borisova E.Y., Kozina, I.B (2015). Neuropsychological Approach to the Study of Special Aspects of Development of Preschool Children with Psychoverbal Pathology. Review of European Studies, 7 (8), 52-59. DOI: 10.5539/res.v7n8p52

Elkonin, B.D. (1992). Crisis of childhood and the bases for projection of the forms of child development. Psychology issues, 3-4, 7-13

Prihozhan, A. M. \& Tolstyh N. N. (2005). Psychology of orphanhood. St. Petersburg: Peter.

Shalaeva, S.L. (2005). Social and ontological status of childhood in the society system. Yoshkar-Ola: MGPI

Shalaeva, S.L., Shalaeva, A.V. (2015).Axiological analysis of intergenerational relations in a globalized society: myth and reality. Review of European Studies, 7 (8), 246-252.

DOI: $10.5539 /$ res.v7n8p246 